\begin{tabular}{l|c|l}
\hline \hline Biological and & Vol. 5(2): 307-314, 2021 & $\begin{array}{l}\text { ISSN: 2002-6153 } \\
\text { Biol. Appl. Environ. Res. } \\
\text { www.baerj.com } \\
\text { editor@a baerj.com }\end{array}$ \\
\hline
\end{tabular}

\title{
Dietary Thepax Effects on Intestinal Morphometry and Liver Histology in Young Common Carp (Cyprinus carpio L.)
}

\author{
Batool H. Al-Mhanawi ${ }^{1}$, Khalidah S. Al-Niaeem ${ }^{2} \&$ Riyadh A. Al-Tameemi ${ }^{2}$ \\ ${ }^{1}$ Department of Diseases and Poultry Diseases, College of Veterinary Medicine, University \\ of Basrah, Basrah, Iraq; \\ ${ }^{2}$ Department of Fisheries and Marine Resources, College of Agriculture, University of \\ Basrah, Basrah, Iraq
}

"Corresponding author e-mail: kalidah_salim@yahoo.com

\begin{abstract}
The present study was carried out to assess the effect of diet supplemented with thepax on intestinal morphometry of young Cyprinus carpio. Fish mean weights were $13.40 \pm 1.85$ gm and their mean total length $11.07 \pm 1.27$ $\mathrm{cm}$ (30 specimens), which were randomly distributed into three treatments (two replications for each treatment). Fish groups were fed three dissimilar diets up to 60 days. The first group was fed with $0.5 \mathrm{gm}$ thepax $/ \mathrm{kg}$ diet, the second group was fed with $1 \mathrm{gm}$ thepax $/ \mathrm{kg}$ diet and the third group was served as the control group which fed basal diet without thepax.supplementation. The feed was applied twice daily at $3.0 \%$ of the body weight per day for 60 days. The intake of prebiotics (thepax) modified the gastrointestinal tracts. Villus length, villus width, and villus area were significantly $(\mathrm{P}<0.05)$ higher than control in young common carp fed the diet supplemented with thepax $(1 \mathrm{gm} / \mathrm{kg})$. No differences in liver histology are observed between the three experimental feed treatments. No histopathological changes like degeneration, necrosis, leukocyte infiltration, haemorrhage and steatosis were noticed. These results indicated that host-derived prebiotics, especially thepax $(1 \mathrm{gm} / \mathrm{kg})$ has significant potential as an important prebiotic to enhance the nutrients utilization and metabolism through increasing intestinal surface area in young common carp.
\end{abstract}

Keywords: Fish, Cyprinus carpio, Thepax, Intestinal morphometry, Liver histology

\section{Introduction}

One of the issues farmers faced on their aquaculture practices was decreased in water quality due to unconsumed fish feeds and fish wastes. This condition of cultivation may reduce the immune response, facilitate the invasion of opportunistic pathogens and even increase mortality, which cause considerable economic losses and damage the sustainable development (Y1lmaz et al., 2013; Waldemar et al., 2017).

Manipulation of intestinal microflora through the dietary supplementation of prebiotics, also known as bio-friendly agents, is a novel approach to improve the 
gut health, growth performances and wellbeing of farmed aquatic animals (Ring $\varnothing$ et al., 2010; Han et al., 2015).

Prebiotic is expressed as an anon-digestible food ingredient that profitably affects the host by selective stimulating the growth and/ or activation of one or a limited number of bacteria in the intestine that can enhance host health status (Gibson \& Roberfroid, 1995; Olsen et al., 2001; Sahu et al., 2007).

Thepax (prebiotic) is a manipulated product of Saccharomyces cerevisiae yeast cells with controlled reproduction and supplemented with amino acids, minerals and vitamins. These supplementary ingredients have positive effects on growth and provide a favorable intestinal microflora (Boostani et al., 2013). The overall objective was to evaluate the efficacy of dietary thepax supplementation as well as their effects on the intestinal morphometry in the young common carp C. carpio.

\section{Materials and Methods}

A total of 30 live common carps weighing $13.40 \pm 1.85 \mathrm{gm}$ with total length of $11.07 \pm 1.27 \mathrm{~cm}$ were obtained from ponds of Marine Science Centre, University of Basrah and transported to the laboratory (Department of Fisheries and Marine Resources). The fishes were treated in a saturated saline solution to get rid of pathogens and ectoparasites. They were acclimated for 14 days and fed on a standard diet (Table 1).

Fishes were randomly distributed in six tanks: Five fishes per tank of $30 \mathrm{x} 40 \mathrm{x}$ $60 \mathrm{~cm}$. Water quality criteria were controlled by measuring the daily temperature, salinity, $\mathrm{pH}$ and dissolved oxygen.

Fish groups were fed three different diets up to 60 days. The first group was fed with $0.5 \mathrm{gm}$ thepax $/ \mathrm{kg}$ diet, the second group was fed with $1 \mathrm{gm}$ thepax $/ \mathrm{kg}$ diet and the third group was served as the control group which fed basal diet without thepax supplementation.

The intestine and liver of fishes were fixed in $10 \%$ formalin. Paraffin sections were prepared (5-8 microns thick), stained by haematoxylin and eosin (H\&E), and examined by a light microscope (Humason, 1972).

Intestinal morphology parameters (villus height, villus width, villus area, crypth depth and intestinal wall thickness) were measured using an image analysis application software (the extraction of meaningful information from images, mainly from digital images by means of digital image processing techniques), as many villi as possible were measured, up to ten villi per slide and no less than five. The villi were chosen to be as evenly spaced around the intestine sample as possible (Bullerwell et al., 2016).

Differences among groups in terms of intestinal morphometry were tested by one-way analysis of variance (ANOVA) at 0.05 using SPSS 20.

\section{Result and Discussion}

All intestinal morphometry including villus height, villus mid width, villus area, crypt depth and intestinal wall thickness of the intestine samples in response to the dietary thepax administration are shown in Table 2 and Figure 1. 
Among the above intestinal histo-morphological parameters, crypt depth and intestinal wall thickness were not affected by dietary supplementation of thepax. Dietary administration of thepax $(1 \mathrm{gm} / \mathrm{kg})$ significantly $(\mathrm{P}<0.05)$ increased villus height $(0.389 \mu \mathrm{m})$, villus mid-width $(0.161 \mu \mathrm{m})$ and villus area $\left(0.070 \mu \mathrm{m}^{2}\right)$ compared to the control diet.

Prebiotics could improve the intestinal wall thickness, villus height and villus density in animals (Dimitroglou et al, 2010; Azevedo et al., 2016). In the present study, dietary of thepax, histologically influenced the intestinal tract including villus height, villus mid-width and villus area.

For instance, rainbow trout (Oncorhynchus mykiss) fed a prebiotic diet (ergosan plant) showed a significant increase in villus height compared to fish fed the control diet (Heidarieh et al., 2012). Merrifield et al. (2011) reported that prebiotic alginic acid enhanced the enterocyte microvilli in the proximal intestine in juvenile Nile tilapia (Oreochromis niloticus), but not in the distal intestine.

Although dietary supplementation of thepax $(1 \mathrm{gm} / \mathrm{kg})$ significantly $(\mathrm{P}<0.05)$ improved villus height, villus width and villus area, no effects were observed on intestinal wall thickness and crypt depth. This may be due to the fish's need for a long time to dietary prebiotic and then effects on intestinal wall thickness and crypt depth (Merrifield et al., 2011; Rašković et al., 2011).

No differences in liver histology are observed between the three experimental feed treatments. Also, no histopathological changes like degeneration, necrosis, leukocyte infiltration, haemorrhage and steatosis were noticed (Fig. 2).

Liver histopathological examination is one of the powerful tools that can be used effectively to monitor fish health in general, as liver is the main organ associated with the digestive system in fishes. Liver histopathological examination can reveal any adverse effects of feed components especially the novel or innovated ingredients (Rašković et al., 2011, 2013).

Some previous studies showed that some dietary prebiotics do not lead to any adverse effects on liver histology in cultured fish species (Olsen et al., 2001; Merrifield et al., 2011). This agrees with the results of the current study.

To date, very little information is available on the effects of prebiotics on intestinal wall thickness and crypt depth in fishes (Azevedo et al., 2016). Similar to the present results, other works recorded that the addition of each inulin at 5.0 $\mathrm{gm} / \mathrm{kg}$ and Jerusalem artichoke (5.0 or $10.0 \mathrm{gm} / \mathrm{kg}$ ) shown an increase in villus height of intestine of juvenile Nile tilapia (Tiengtam et al., 2015). 
Table 1: Formulation of the experimental diet.

\begin{tabular}{|lc|}
\hline Ingredients & $\%$ \\
\hline Fishmeal & 25.00 \\
\hline Soybean meal & 40.00 \\
\hline Corn meal & 10.00 \\
\hline Barley meal & 10.00 \\
\hline Wheat bran & 10.00 \\
\hline Carboxy methyl cellulose & 2.00 \\
\hline Vit premix & 3.00 \\
\hline Totale & 100 \\
\hline
\end{tabular}

* Sebro Company Turkey

Table 2: Histological measurement of intestinal samples in young common carp fed experimental diets supplemented with thepax for 60 days.

\begin{tabular}{|lccc|}
\hline Parameters & \multicolumn{3}{c|}{ Experimental diets } \\
\hline & $\begin{array}{c}\text { Control } \\
\text { Standard diet }\end{array}$ & $\begin{array}{c}\text { Thepax } \\
(0.5 \mathrm{gm} / \mathrm{kg} \mathrm{diet})\end{array}$ & $\begin{array}{c}\text { Thepax } \\
(1 \mathrm{gm} / \mathrm{kg} \mathrm{diet})\end{array}$ \\
\hline Villus height $(\mu \mathrm{m})$ & $0.310 \pm 0.005^{\mathrm{a}}$ & $0.321 \pm 0.005^{\mathrm{a}}$ & $0.389 \pm 0.002^{\mathrm{b}}$ \\
\hline Villus width $(\mu \mathrm{m})$ & $0.127 \pm 0.006^{\mathrm{a}}$ & $0.139 \pm 0.004^{\mathrm{a}}$ & $0.161 \pm 0.006^{\mathrm{b}}$ \\
\hline Villus area $\left(\mu \mathrm{m}^{2}\right)$ & $0.041 \pm 0.008^{\mathrm{a}}$ & $0.047 \pm 0.008^{\mathrm{a}}$ & $0.070 \pm 0.003^{\mathrm{b}}$ \\
\hline Crypt depth $(\mu \mathrm{m})$ & $0.026 \pm 0.003^{\mathrm{a}}$ & $0.026 \pm 0.002^{\mathrm{a}}$ & $0.028 \pm 0.003^{\mathrm{a}}$ \\
\hline $\begin{array}{l}\text { Intestinal wall thickness } \\
(\mu \mathrm{m})\end{array}$ & $0.098 \pm 0.003^{\mathrm{a}}$ & $0.100 \pm 0.002^{\mathrm{a}}$ & $0.101 \pm 0.004^{\mathrm{a}}$ \\
\hline
\end{tabular}

Different letters in the same row are significantly different $(\mathrm{P}<0.05)$. 

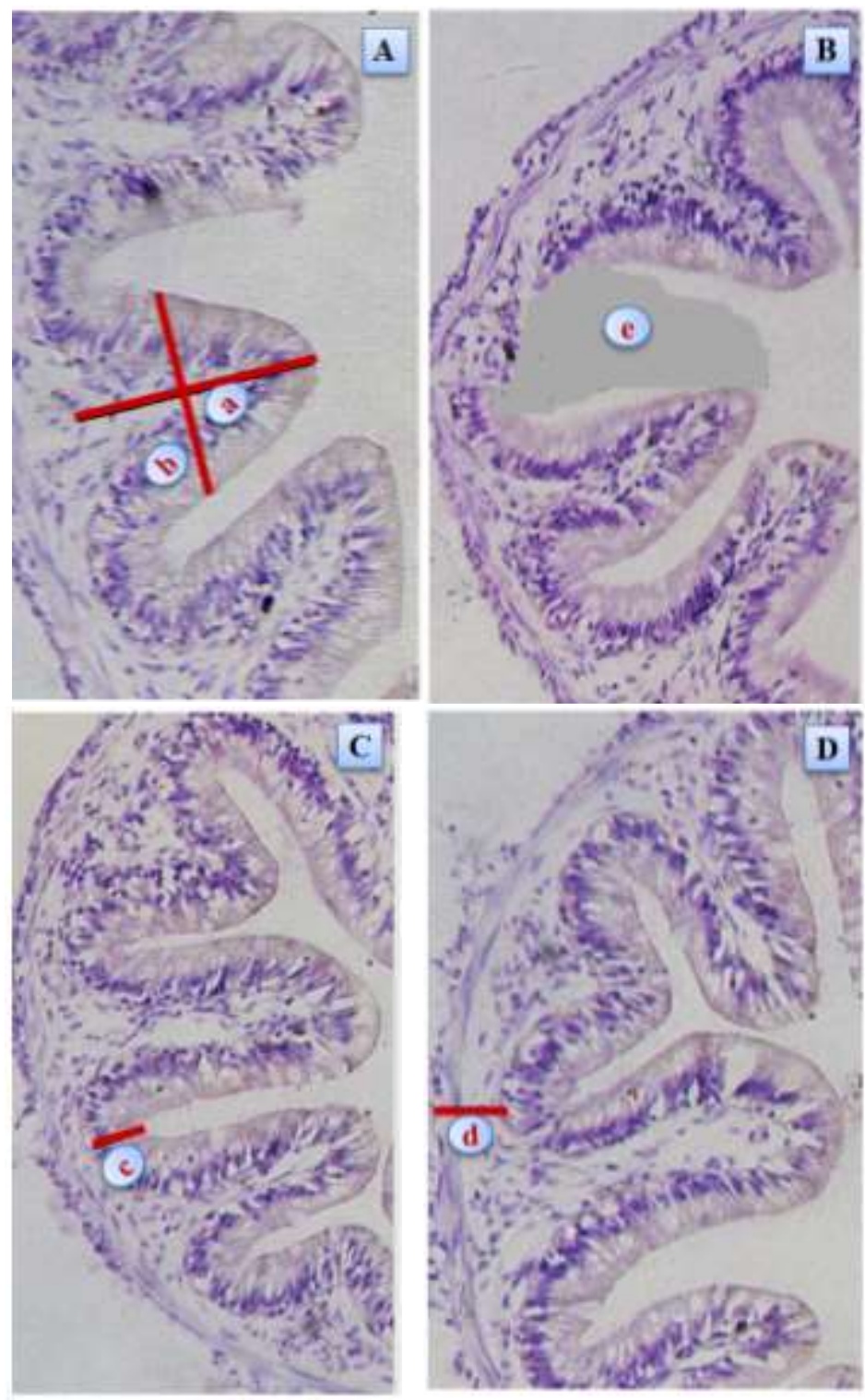

Figure 1: Intestinal morphometry of the intestine region. A \& D: Control, B: $0.5 \mathrm{gm}$ Thepax/kg diet, C: $1 \mathrm{gm}$ thepax/kg diet. Points of measurements for histological analysis of intestinal cross-sections: (a) villus length, (b) villus width, (c) crypt depth, (d) intestinal wall thickness, (e) villus area. (H\&E, $400 \mathrm{X}$ ). 

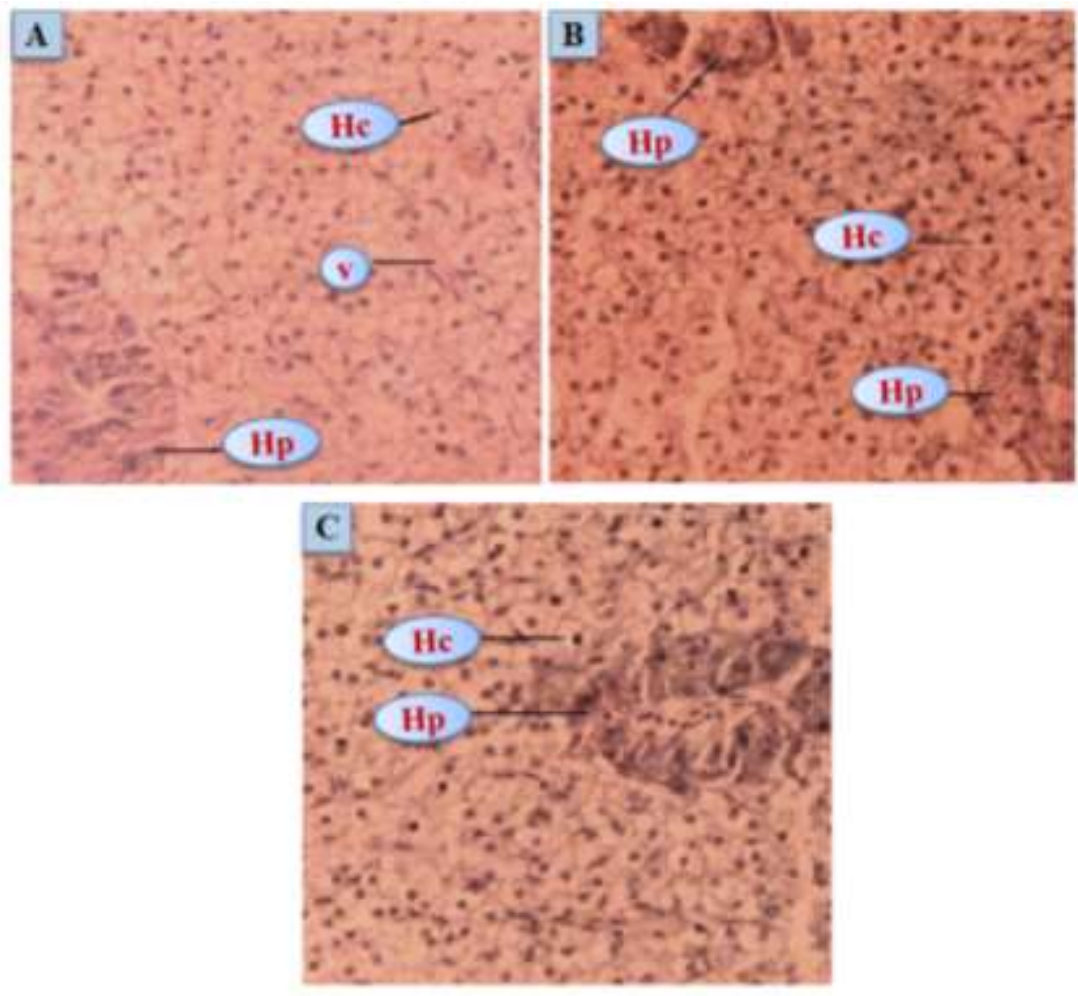

Figure 2: Fish liver histology. A: Control, B: $0.5 \mathrm{gm}$ Thepax/kg diet, C: $1 \mathrm{gm}$ thepax/kg diet. Hc: hepatocyte, Hp: hepatopancreas, v: vein. (H\&E, $400 \mathrm{X})$.

\section{References}

Azevedo, R.V.; da Silva-Azevedo, D.K.; Dayane, K.; dos Santos-Júnior, J.M.; Fosse-Filho, J.C.; de Andrade, D.R.; Tavares-Braga, L.G. \& Vidal-Júnior, M.V. (2016). Effects of dietary mannan oligosaccharide on the growth, survival, intestinal morphometry and nonspecific immune response for Siamese fighting fish (Betta splendens Regan, 1910) larvae. Lat. Am. J. Aquat. Res., 44(4): 800-806. DOI:10.3856/vol44-issue4-fulltext-15.

Boostani, A.; Mahmoodian Fard, H.R.; Ashayerizadeh, A. \& Aminafshar, M. (2013). Growth performance, carcass yield and intestinal microflora populations of broilers fed diets containing thepax and yogurt. Braz. J. Poult. Sci., 15(1): 1-6. DOI:10.1590/S1516-635X2013000100001.

Bullerwell, C.N.; Anderson, D.M.; Lall, S.P. \& Collins, S.A. (2016). Growth performance, proximate and histological analysis of rainbow trout fed diets containing Camelina sativa seeds, meal (high-oil and solvent-extracted) and oil. Aquaculture, 452: 342-350. DOI:10.1016/j.aquaculture.2015.11.008.

Dimitroglou, A.; Davies, S.J.; Sweetman, J.; Divanach, P. \& Chatzifotis, S. (2010). Dietary supplementation of mannan oligosaccharide on white sea bream (Diplodus sargus L.) larvae: Effects on development, gut morphology and 
salinity tolerance. Aquac. Res., 41(9): 245-251. DOI:10.1111/j.1365-2109. 2010.02513.x.

Gibson, G.R. \& Roberfroid, M.B. (1995). Dietary modulation of the human colonic microbiota: Introducing the concept of prebiotics. J. Nutr., 125(6): 14011412. DOI:10.1093/jn/125.6.1401.

Han, B.; Long, W.-Q.; He, J.-Y.; Liu, Y.-J.; Si, Y.-Q. \& Tian, L.-X. (2015). Effects of dietary Bacillus licheniformis on growth performance, immunological parameters, intestinal morphology and resistance of juvenile Nile tilapia (Oreochromis niloticus) to challenge infections. Fish Shellfish Immunol. 46(2): 225-231. DOI: 10.1016/j.fsi.2015.06.018.

Heidarieh, M.; Mirvaghefi. A.R.; Akbari. M.; Farahmand, H.; Sheikhzadeh. N.; Shahbazfar, A.A. \& Behgar, M. (2012). Effect of dietary ergosan on growth performance, digestive enzymes, intestinal histology, hematological parameters and body composition of rainbow trout (Oncorhynchus mykiss). Fish Physiol. Biochem., 38(4): 1169-1174. DOI:10.1007/s10695-012-9602-8. Humason, G.L. (1972). Animal tissue techniques $3^{\text {rd }}$ edition, W.H. Freeman, San Francisco: $641 \mathrm{pp}$.

Merrifield, D.L.; Harper, G.M.; Mustafa, S.; Carnevali, O.; Picchietti, S. \& Davies, S.J. (2011). Effect of dietary alginic acid on juvenile tilapia (Oreochromis niloticus) intestinal microbial balance, intestinal histology and growth performance. Cell Tissue Res., 344(1): 135-146. DOI:10.1007/s00441-010$1125-\mathrm{y}$.

Olsen, R.E.; Myklebust, R.; Kryvi, H.; Mayhew, T.M. \& Ring ø, E. (2001). Damaging effect of dietary inulin on intestinal enterocytes in Arctic charr (Salvelinus alpinus L.). Aquac. Res., 32(11): 931-934. DOI:10.1046/ j.13652109.2001.00626.x.

Rašković, B.S.; Stanković, M.B.; Marković, Z.Z. \& Poleksić, V.D. (2011). Histological methods in the assessment of different feed effects on liver and intestine of fish. J. Agric. Sci., 56(1): 87-100. DOI:10.2298/JAS1101087R.

Rašković, B.; Jarić, I.; Koko, V.; Spasić, M.; Dulić, Z.; Marković, Z. \& Poleksić, V. (2013). Histopathological indicators: A useful fish health monitoring tool in common carp (Cyprinus carpio Linnaeus, 1758) culture. Cent. Eur. J. Biol., 8: 975-985. DOI:10.2478/s11535-013-0220-y.

Ring $\varnothing$, E.; Olsen, R.E.; Gifstad, T.Ø.; Dalmo, R.A.; Amlund, H.; Hemre, G.-I. \& Bakke, A.M. (2010). Prebiotics in aquaculture: A review. Aquac. Nutr., 16(2): 117-136. DOI:10.1111/j.1365-2095.2009.00731.x.

Rossi, W. Jr.; Min Ju, M.; Hume, M.E.; Tomasso, J.R. \& Gatlin III, D.M. (2017). Nutrition of red drum, Sciaenops ocellatus L.: An additional evaluation of the effects of soya-based diets and supplemental prebiotic. Aquac. Res., 48(10): 5224-5234. DOI:10.1111/ are.13334.

Sahu, S.; Das, B.K.; Mishra, B.K.; Pradhan, J. \& Sarangi, N. (2007). Effect of Allium sativum on the immunity and survival of Labeo rohita infected with Aeromonas hydrophila. J. Appl. Ichthyol., 23(1): 80-86. DOI:10.1111/j.14390426.2006.00785.x. 
Tiengtam, N.; Khempaka, S.; Paengkoum, P. \& Boonanuntanasarn, S. (2015). Effects of inulin and Jerusalem artichoke (Helianthus tuberosus) as prebiotic ingredients in the diet of juvenile Nile tilapia (Oreochromis niloticus). Anim. Feed Sci. Technol., 25: 120-129.

Yılmaz, S.; Ergün, S. \& Soytaş, N. (2013). Dietary supplementation of cumin (Cuminum cyminum) preventing streptococcal disease during first-feeding of Mozambique tilapia (Oreochromis mossambicus). J. Biosci. Biotechnol., 2(2): 117-124. 